ENTREVISTA / INTERVIEW 



\title{
Política Externa Brasileira
}

\author{
Baśl llele Malomalo, Camila Alves da Costa e \\ MÔNica Dias Martins
}

Em meio aos preparativos para o VI Encontro Tensões Mundiais, uma atividade se destacou: a entrevista em 7 de maio de 2018 na Rádio Universitária FM, uma antiga parceria do Observatório das Nacionalidades/ON, firmada à época do saudoso amigo, o jornalista Agostinho Gósson. Para discutir o tema do evento "Política Externa Brasileira: novos rumos e desafios epistemológicos", estiveram presentes os professores Bas'Ilele Malomalo (Universidade da Integração Internacional da Lusofonia Afro-Brasileira/ UNILAB), Camila Costa (Universidade Paulista) e Mônica Martins (Universidade Estadual do Ceará/UECE). Fomos recebidos pela produtora do programa, Raquel Chaves, e pelo apresentador Pedro Vitor, com quem iniciamos uma proveitosa troca de ideias antes mesmo de irmos ao ar.

Pedro Vitor: Bom dia. Nesta segunda-feira, 7 de maio de 2018, vamos conversar sobre a política externa brasileira contemporânea e sua história, tema do Encontro Tensões Mundiais, que chega a sua sexta edição e começa hoje em Fortaleza. O evento prossegue até 10 de maio de 2018, no campus Itaperi da UECE e no campus Liberdade da UNILAB, em Redenção. Desde o século 19, o Brasil busca o estreitamento político, econômico e social com outros países, mantendo alguns princípios na política externa, como soberania, desenvolvimento nacional e autonomia. Mas qual a realidade hoje? Como o Brasil tem pensado essas articulações? Para debater este assunto temos o prazer de receber agora, nos estúdios da Rádio Universitária FM, Mônica Martins, uma das organizadoras do evento, coordenadora do Observatório das Nacionalidades e professora da UECE, Camila Costa, pesquisadora do ON, professora de Relações Internacionais e do curso de Direito e coordenadora do curso de Relações Internacionais na Universidade Paulista, e Bas'Ilele Malomalo, professor do curso de graduação em Relações Internacionais e do mestrado 
interdisciplinar em Humanidades, da UNILAB, na Bahia. Por que a política externa brasileira é o foco central deste encontro?

Mônica: O ON compreende que para uma nação se firmar é importante que ela se projete interna e externamente. As duas coisas estão muito relacionadas. Ao tempo em que temos uma autopercepção de nossa imagem de brasileiros, a política externa nos ajuda a perceber quem somos. Importante ver essa relação: o Brasil, nação reconhecida pelo seu povo e não usurpada por alguns governantes, e que se projeta internacionalmente, tendo algo a oferecer ao mundo. Estamos notando que de 2016 para cá tem havido um redirecionamento em nossa política externa e achamos que chegou a hora, enquanto grupo de pesquisa, de reunir colegas da UECE, UNILAB, UNILA, UNIP, UNIFOR e UFPE para discutir qual o papel da universidade nesse processo de definição da política externa. Ela não é restrita a militares, diplomatas, governo. Como acadêmicos e intelectuais, temos que esclarecer e discutir nosso papel. Então, de 7 a 10 vamos nos reunir, sendo três dias na UECE, em Fortaleza, e um dia na UNILAB, em Redenção, para aprofundar nosso conhecimento e divulgar junto à população cearense e brasileira o que pensamos a respeito.

Pedro Vitor: Camila, eu queria saber qual é a importância desse debate, das relações internacionais e suas consequências para o Brasil hoje.

Camila: O Brasil vinha caminhando, até pelos menos 2016, com uma política externa que queria colocar o país numa posição de protagonismo. E conseguimos. Nós éramos respeitados internacionalmente, convidados ao debate internacional. Em alguns casos, inclusive, a presença do Brasil era exigida, como aconteceu no acordo entre Irã e Estados Unidos. O Irã disse que só negociaria se o presidente Lula participasse dessas negociações. Chegamos ao ponto de nos colocarmos como atores relevantes no cenário internacional, determinarmos a vontade do povo brasileiro e não seguir pelas vontades de outros povos, e agora vemos esse retrocesso. Não podemos debater, nos colocar, nos relacionar... existe uma situação de ingovernabilidade dentro do Brasil hoje. Enquanto isso, quebramos acordos internacionais com os BRICS, a Zona de Paz e Cooperação do Atlântico Sul/ZOPACAS, acordos 
de defesa, de comércio, parcerias culturais etc. A população precisa participar desse debate e não se pode silenciar, especialmente na academia. Que bom ter esse espaço na Rádio Debate, mais uma vez fico muito grata por ter esse espaço aqui na FM Universitária.

Pedro Vitor: Professor Bas'Ilele, a professora Camila falou sobre a imagem do Brasil no exterior. É um ponto muito importante e acredito que vai estar muito presente nos debates que vão acontecer nesse encontro. Como o senhor analisa a visão, a imagem do Brasil no exterior na atual conjuntura política?

Bas'Ilele: Na atual conjuntura política a situação do Brasil está difícil, como todo mundo sabe, a partir do acontecimento de 2016. O golpe interno colocou o Brasil em uma situação muito difícil e esse Brasil está em busca de se redefinir, mas, como as professoras colocaram, o que faz o Estado é o povo, não é? Eu sou da República Democrática do Congo e a gente tem um provérbio que diz que a governança é do povo. Em outras palavras, o governante depende do povo. Então o debate na UECE, na UNILAB, tem a ver primeiro com a população, e a gente quer que todo mundo venha participar, independentemente de ser da academia ou não. Nossa fala tem relação com esse grande projeto que é a Universidade de Integração Internacional da Lusofonia Afro-Brasileira, que nasce em 2012, mas o projeto começa em 2008. Tínhamos um quadro de sucesso, desde 2003, com os governos Lula e Dilma, quando o Brasil se colocou no cenário internacional como nunca tinha se colocado antes. Isso aí todo mundo sabe. Agora veja que a UNILAB vai ser uma universidade com a política da interiorização, internacionalização. A universidade se constitui no Maciço de Baturité e com resultado muito positivo. Atende pessoas que não teriam oportunidade de fazer um curso superior em todas as áreas que a gente tem, desde saúde, engenharia, agronomia, que é nossa proposta. É uma proposta diferenciada. Não é a agronomia, por exemplo, do agronegócio. Tem a ver com o camponês, tem a ver com aquele agricultor familiar. Então foi esse projeto que o Brasil tinha trazido, mas nesse momento o país passa por dificuldades, crises e até ameaças em relação a esse projeto, tanto esse que acabei de dizer, da UNILAB, como igualmente o da UNILA, que é a proposta na parte do sul do país, que agrega as populações 
da América Latina e tem capacidade de incorporar os povos indígenas, como nós aqui na UNILAB temos uma grande presença da população negra. Não sei as estatísticas, mas, por exemplo, no campus do Malês, no recôncavo baiano, chegamos a 98\% de jovens negros. Você tem o equilibro da academia do ponto de vista racial, de gênero, em termos docentes. Essas construções, quando você faz um espaço internacional, têm consequências muito positivas para a vida das pessoas. Esse foi o Brasil que se projetou desde 2003; na conjuntura atual, nós estamos sob ameaça de perder esses projetos que sustentam nosso país e nosso povo.

Pedro Vitor: Professor, quais as consequências, por exemplo, das mudanças na política externa do Brasil nos últimos dois anos, no que diz respeito a outros países, por exemplo, do continente africano?

Bas'Ilele: Olhando pela África, e acho que a Camila pode trazer para a gente também a questão do Oriente Médio, tem uma dimensão regional. Tudo bem, a gente está falando de uma política externa, mas ela tem que estar acompanhada de uma política interna, uma política regional tanto do Estado quanto do Governo Federal, na sua dimensão mais complexa. O que a gente percebeu, pelo menos nas pesquisas que estamos fazendo, foi que de 2003 até 2010 tivemos um quadro muito positivo em termos do antigo paradigma Sul-Sul, a chamada cooperação solidária. Esse é o paradigma da conferência de Bandung, de 1955, quando a Ásia vai confrontar os imperialismos europeus, e é nesse processo que a África também colonizada vai se movimentando para se libertar. Então o paradigma da cooperação solidária tem a ver com a luta de povos que vão se libertar das dominações estrangeiras. Quando o Brasil, através do governo Lula, retoma a cooperação Sul-Sul, ele está trazendo de volta a luta de povos. Internamente, seria a luta do povo cearense, do nordestino, do povo da Bahia. Muitas vezes a gente pensa na política externa como algo distante. Não necessariamente. A política externa é algo próximo de nós, até no ponto que já falei aqui: é a presença de nossos jovens, filhos de agricultores, gente de família pobre, muito simples, que teve acesso à educação. Então essa política externa brasileira fez isso em relação à dimensão regional interna. Lá fora do país, de 2016 
para 2017, as notícias foram tristes, porque a primeira movimentação foi querer fechar as embaixadas brasileiras em países africanos, em nome do discurso de não ter dinheiro e não sei o que mais. A questão é que um paradigma colonial e economicista não consegue enxergar o que as pesquisas vinham mostrando e têm mostrado. O Brasil lucrou, lucrou muito na sua cooperação para com a África. Então é mentira achar que a relação com a África não ajuda. Economicamente isso ajuda, sem falar da dimensão cultural, de outros espaços sociais e assim por diante. Essa política precisa ser preservada, o Brasil tem muito a ganhar com a África e a África tem muito a ganhar com o Brasil.

Pedro Vitor: Então o senhor diria que, por exemplo, a posição de alguns agentes políticos que desejavam fechar justamente essa relação, essas pontes entre o Brasil e a África, são posturas que provinham mais de uma ideia colonial do que necessariamente capitalista liberal? Porque o Brasil estava lucrando, continua lucrando com essas relações com países africanos. Então queriam fechar mais por uma mentalidade colonial do que capitalista?

Bas'Ilele: Isso. A disputa de 2016 em relação ao golpe da presidente Dilma tem a ver com a disputa do projeto da nação e a questão do paradigma. As pessoas que a derrubaram colocaram um paradigma que não ter nada a ver com o povo, é um paradigma atrelado ao agronegócio, colonial, racista, machista, contra nordestinos, imigrantes, comunidade LGBT. Esse paradigma é o que a gente não quer. Vou dar um caso concreto: nós, da UNILAB do Ceará, recebemos uma indicação do novo reitor, e quando ele chega a primeira coisa que faz é tentar cortar o processo de seleção dos estudantes estrangeiros, que é a coluna da nossa universidade internacional. Então ao fazer isso você destrói uma política.

Pedro Vitor: Justamente esse espaço de troca que é propiciado pela UNILAB, essa troca entre países africanos e Brasil, tanto intelectual como cultural.

Bas'Ilele: Isso. Houve bastante resistência e a pessoa recuou. Isso porque se parte da ideia de que África é um continente pobre. Então esse paradigma não serve. Nesse momento a União Africana está debatendo o chamado mercado livre continental, e quando se fala do mercado livre nós sabemos da potência que a África tem. 
Pedro Vitor: A China está com o olho bem grande, o Oriente Médio também tem investido pesado.

Bas'Ilele: A gente vê essas cooperações. Mas o Brasil está perdendo, porque com sua crise interna e esse preconceito (o racismo, de que estávamos falando) não vai conseguir estabelecer essas relações econômicas e culturais que vinha fazendo com África. Esse é o perigo que se coloca. A União Africana estabeleceu a chamada diáspora africana como a sua sexta região. Porque tem norte, sul, oeste, leste e região central. Eram cinco, mas agora vem a diáspora como a sexta região. E qual é a diáspora que tem a grande população negra fora da África? É o Brasil. Imagina isso em termos de intercâmbio e trocas econômicas, comerciais.

Mônica: E de autoestima.

Pedro Vitor: A segunda maior população negra do mundo é a brasileira, só perde para a Nigéria.

Bas'Ilele: É dessas questões que estamos falando. Não basta a gente querer estabelecer comércio com a União Europeia, esquecendo esse grande continente. Quando a gente fala de cooperação, da política externa, a gente tem que valorizar esse outro paradigma.

Pedro Vitor: Professora Camila, o que o professor falou é muito importante: a capacidade de um país poder gerir suas crises internas como a que a gente vem vivendo atualmente sem abalar as suas relações internacionais. O Brasil tem sido competente ou não nesse sentido?

Camila: De maneira alguma. Na verdade, o que nos chamou a atenção em reuniões internacionais, sobretudo em encontros dos BRICS, é a possibilidade de os países negociarem de igual para igual com os Estados Unidos e a União Europeia. Foi chamada a atenção do Brasil, porque a crise de ingovernabilidade interna não justificava a quebra de acordos externos. É necessário que um país saiba lidar com a política interna ao mesmo tempo em que lida com a política externa. A gente não pode isolar uma da outra. As duas são complementares, uma surge da outra. A política externa deve ser baseada na determinação da vontade da população, o que não se vê no governo ilegítimo depois do golpe. Existe uma expectativa de que talvez nós tenhamos um novo governo, e a partir daí 
podemos caminhar. O tempo histórico não desacelera a história, o trem da história passa e nós não podemos parar por dois anos ou três anos para resolver os problemas internos enquanto deixamos de lado nossas parcerias externas, comerciais, de defesa, culturais, a ZOPACAS, a própria parceria com o continente africano.

Pedro Vitor: Isso tem a ver com as diferenças entre política de governo e de Estado? Uma coisa é uma política que se fecha no governo, outra coisa é uma política que se estende independente do governo que assume.

Camila: Exatamente, falta ao Brasil a política de Estado. Temos uma política de governo que, infelizmente, não tem continuidade, e isso é altamente prejudicial. Agora a gente tem que entender que se nós queremos esse protagonismo internacional, que nós estávamos começando a conquistar, aspirando a um assento no Conselho de Segurança da ONU, que sempre foi uma luta do Brasil, precisamos voltar a ser considerados. Hoje, nós somos olhados como uma república de bananas e desrespeitados, quando na verdade há dois anos, há três anos o Brasil era consultado em vários assuntos de disputa internacional. Então estamos falhando, e muito, na capacidade de lidar com essa crise interna enquanto continuamos nos relacionando com o mundo. Há essa falta de entendimento de que a política externa ajuda a nos reconhecer como nacionais. Nós somos mais brasileiros quanto mais nos relacionamos com o estrangeiro. É a nossa política externa que diz onde estamos, quais as nossas vontades, o que podemos, o que queremos. Uma não é excludente da outra, não existe isso. Esse discurso de que a gente não pode investir em bolsas para estudantes estrangeiros enquanto os estudantes brasileiros não têm condições é ultrapassado, já é muito batido, é um discurso que se prova errado. Nós lucramos com as parcerias, especialmente com o continente africano. E tínhamos também uma posição de protagonismo no Oriente Médio.

Pedro Vitor: Você pode falar um pouquinho da posição de protagonismo e como se encontra agora?

Camila: Veja, 60\% do açúcar consumido no Afeganistão é brasileiro. A forma como o Irã, na época o presidente Ahmadinejad, se colocou e disse que só ia permitir a visita dos conselheiros da 
ONU se o presidente Lula negociasse e mediasse essa negociação mostra que o Brasil tinha chegado a ambientes que nem esperávamos. Nós pensávamos em nos colocar como protagonistas no continente americano e no continente africano, e alcançamos na verdade as fronteiras do Afeganistão, do Paquistão.

Pedro Vitor: Os dois em situação de quase guerra, não é isso?

Camila: Quase guerra com os Estados Unidos, que se colocava nessa posição de império, de polícia do mundo. O Brasil era consultado, tinha voz e vez. Nossos diplomatas e representantes eram respeitados nesse momento. E agora a gente rompeu essas parcerias, rompeu com esses laços, nos alinhamos novamente com os Estados Unidos e queremos essa aliança com a União Europeia, que também não está se entendendo. Então, retrocedemos com esse governo ilegítimo, andamos para trás e muito, muito rapidamente.

\section{INTERVALO}

Pedro Vitor: Professora Mônica, quando elegemos um(a) presidente, poucos brasileiros têm a ideia de que aquele cargo é muito importante não só para nossa nação, mas também para outros países. Com a globalização, internet, mercado financeiro, cada vez mais fica evidente que o poder político de um país não afeta só aquele país, mas muitos outros. Elegemos pensando em saúde, educação, segurança. Mas poucas vezes pensamos na relevância da política externa na hora de votar. No caso de dois candidatos, por exemplo, muito parecidos no que diz respeito a saúde, educação, enfim... faz sentido pensar nas relações internacionais para definir o voto?

Mônica: Faz todo sentido, Pedro, pensar isso. Nossa percepção é de que a política externa está profundamente ligada com as ações que se constroem dentro de uma nação. Então, por exemplo, considero, ouvindo a fala do Bas'Ilele, que em nenhum momento a autoestima do brasileiro foi maior do que quando tivemos um paradigma de relações internacionais ou de política externa brasileira que fugia da tradição e buscava apostar na inovação de uma cooperação solidária Sul-Sul. Nesse momento nos beneficiamos 
enormemente do ponto de vista da nossa autoestima. Nós nos sentimos fortes, grandes, solidários, querendo construir um novo mundo, uma coisa diferente. Então acho que é uma das coisas a se olhar. Há muito tempo que a gente vem chamando a atenção a esse ponto crucial que você apontou. É muito fácil os candidatos apontarem uma mesma proposta para violência, segurança, habitação. Quem vai ser contra? Ainda mais após esse desastre terrível em São Paulo que escancarou o descaso como uma das coisas mais sagradas do homem que é seu lar ${ }^{1}$ Então é muito provável que todos os candidatos, do Bolsonaro à Manuela D'Ávila, tenham um discurso semelhante com educação. Agora, em relação à política externa, aí acho que é um grande divisor de águas que é fundamental observarmos. Na maioria das vezes, candidatos nem se preocupam em apresentar um plano, uma proposta para a política exterior do país. Isso não entra. O silêncio em relação à política externa já é um indicador do caminho desse candidato. Provavelmente ele terá uma postura de alinhamento automático com as grandes potências.

Pedro Vitor: Se você não tem um plano, entra no automático.

Mônica: Exatamente. Você tocou num ponto fundamental que revela nossa preocupação nesse ano eleitoral de 2018, com uma polarização enorme, um ódio que se manifesta de mil maneiras possíveis, como no assassinato da Marielle, que se manifesta ao silenciar professores e proibir que a UFC, onde se hospeda esta rádio maravilhosa, desse um curso sobre o golpe de 2016, alegando que não se pode falar. Então é crucial agora trazermos esse debate no momento em que vai se escolher não só o presidente, mas representantes do Parlamento que irão compor a comissão de relações internacionais e defesa nacional, que pouquíssima

1 Em $1^{\circ}$ de maio de 2018 ocorreu um incêndio seguido de desabamento no edifício Wilton Paes de Almeida, ocupado por 455 moradores do Movimento Social de Luta por Moradia (MLSM). As buscas por vítimas foram encerradas contando quatro mortos identificados: Ricardo Oliveira Galvão Pinheiro, 38 anos; Francisco Lemos Dantas, confeiteiro, 56 anos; Wendel e Werner da Silva Saldanha, gêmeos de 10 anos. Cinco pessoas não foram encontradas: Gentil de Souza Rocha, 53 anos; Selma Almeida da Silva, 40 anos, catadora de materiais recicláveis e mãe dos irmãos mortos; Eva Barbosa, 42, faxineira, e seu marido, Valmir de Souza Santos; e o advogado Alexandre de Menezes, 40 anos. 
gente acompanha. Ela existe na Câmara dos Deputados. Então, ao elegermos um deputado federal, qual vai ser a política dele em relação à comissão de defesa nacional e relações internacionais? Vamos eleger senador; qual a posição dele? Não temos que perguntar isso apenas ao candidato à presidência, temos também que nos preocupar com a posição dos candidatos ao senado e à Câmara de Deputados, conhecer a posição deles em relação à política externa brasileira. Essas duas comissões são centrais. Na verdade, o presidente não pode fazer nada sem o aval do congresso, nada! É o congresso que define se vai entrar no Mercosul, se vai sair do Mercosul, se vai apoiar a ZOPACAS e os BRICS. Essa comissão é fundamental e é pouquíssimo acompanhada. Ninguém pergunta aos candidatos a deputado federal e senador qual é a postura deles em relação à política externa.

Pedro Vitor: Como a professora Mônica acabou de falar, é importantíssimo definir isso também para o legislativo, até porque tem gente que "ah, vou votar nesse candidato por que ele defende os animais". É importante a gente voltar a se ligar nessas bandeiras para escolhermos os nossos candidatos.

Mônica: E aí entra a questão que a Camila estava abordando sobre a Palestina, por exemplo. Hoje em dia nós temos duas situações gravíssimas no mundo. A do povo Saharaui, que é bastante desconhecida, a última colônia na África. O povo Saharaui foi dominado pela Espanha por muito tempo, e a Espanha prometeu dar independência. Eles criaram a Frente Polisário e a Espanha simplesmente passou o destino dessa população para o Marrocos. O Marrocos exerce uma dominação brutal, separou as famílias e fez um muro. É um povo de beduínos, nômade, que tem uma cultura riquíssima no Oriente Médio. Então a situação é triste demais. O professor Gimeno, um espanhol, irá publicar no próximo número de Tensões Mundiais um artigo tratando dessa situação especial. O Brasil reconheceu a Frente Polisário e também o Estado da Palestina. Só lembrando que a ONU prometeu, no final da Segunda Guerra, criar dois Estados, Israel e Palestina, e a gente sabe o que aconteceu dali para cá. É importante para nós, brasileiros, sabermos que somos um povo solidário, que cooperamos... a nossa autoestima vai lá para cima e a gente começa a se ver de 
maneira diferente. Acho que comecei a me ver de maneira diferente nesse tempo em que o paradigma da cooperação Sul-Sul, como Bas'Ilele falou, foi vigente. Conheci Moçambique, Guiné-Bissau, Cabo Verde. Que maravilha! Como era bom estar lá em Maputo, Luanda, Bissau... era tão interessante a gente ser brasileiro e nos encontrarmos como irmãos, num clima de muita solidariedade. Isso foi em 2011, não faz tanto tempo.

Bas'Ilele: É importante saber, e a Mônica acabou de colocar, quem a gente vai eleger. Mas queria tocar na questão da militarização. Temos um candidato à presidência da república que foi no auditório de uma instituição israelita e mostrou seu racismo, seu machismo publicamente. Esse povo judeu, que tanto sofreu, vive em um Estado de Israel cheio de contradições, um Estado militarizado. Quem acompanha o debate sobre as migrações africanas está vendo a expulsão de imigrantes em todo o território. É uma contradição total, é uma política muito agressiva. A gente sabe que nem todos os judeus pensam da mesma forma, mas há uma ala que a gente, olhando o passado que tiveram de sofrimento, vê contradições. Isso vai refletir igualmente nesse período de transição de golpe que a gente está falando. Houve um concurso de relações internacionais em uma universidade onde um ponto virou polêmico. O que se soube depois é que a embaixada de Israel teve que intervir para tirar esse ponto. São coisas que a gente nem imaginava. Então, o povo brasileiro, nós estamos falando de um povo que resiste. Olhando especificamente para o Nordeste, nós resistimos contra a escravidão, resistimos contra a ditadura militar no país, nós sempre resistimos desde Canudos e outros, e dia-a-dia nos movimentos sociais. Esse povo tem que retomar o rumo do país em relação à política externa para saber quem deve eleger e qual é a agenda desses governantes em relação à política externa. Olha o nosso congresso e o Executivo brasileiro: muitos são descendentes de imigrantes. Na composição do Brasil, retirando a população indígena, quem não é filho de imigrante nesse país? Por isso é preciso pensar na política externa brasileira com bastante carinho e cuidado. Porque essa formação tem a ver com esses lugares diferentes de onde nossos avós vieram. Acho que esse ponto merece atenção. 
Pedro Vitor: Bom, queria comentar a participação da ouvinte Terezinha Meireles. Ela está amando o programa e disse que a fala do professor Bas'llele foi sensacional: “O que me atrai é que sempre vocês conseguem trazer pessoas competentes para avaliar essa atual conjuntura política do Brasil. Gostaria de indicar a leitura de um livro que, penso, tem a ver com o assunto: A idiotice ao alcance de todos e a necessidade de uma nova esquerda, do professor Gilvan Rocha." Obrigado, Terezinha, por sua participação.

Mônica: A Rádio Debate é um dos poucos lugares onde há essa discussão. Debater é fundamental, o pensamento único só atrai coisas erradas. Eu lembro quando houve o encontro dos BRICS em Fortaleza, em 2014. Havia no Observatório das Nacionalidades pesquisadores que defendiam que o Brasil estava assumindo uma posição subimperialista; outros diziam que não, que era muito bom o que o Brasil estava fazendo. Então essa polêmica que a Rádio Debate consegue trazer é fundamental no momento atual para que o pensamento único não seja dominante.

Pedro Vitor: Professora Camila, depois do afastamento da presidenta Dilma para ser julgada quem assumiu o Ministério das Relações Exteriores foi o José Serra. Ele falou que a política externa do PT era pautada pela ideologia e não por uma perspectiva plural. Eu não sei se era o Serra cientista falando do Serra político, mas queria saber de você, como cientista: fazendo um balanço desses últimos 20 anos, a política externa do Brasil tendeu a ser mais ideológica ou não?

Camila: As ideologias estão aí, a gente está tratando de política e é impossível isolar o homem da sua posição de direita, esquerda ou centro. Mas havia também um objetivo muito claro que era nos tornar membro do Conselho de Segurança da ONU. Foi aí que o presidente Lula visitou e reconheceu a Palestina, não só o Estado Israelense militarizado, que, como professor Bas'Ilele coloca, é tão paradoxal. Porque os judeus passaram por isso e hoje repetem com a população de palestinos. Então a política externa tinha, lógico, algo de ideológico. Mas ela foi colocada em prática com tanto sucesso que éramos reconhecidos no exterior, o Brasil era referência. Quando a gente dizia que era brasileiro no exterior, as pessoas perguntavam como a gente fazia para sair da crise, 
como acompanhar esses avanços pelos quais vocês estão passando também.

Pedro Vitor: Era referência não só para América Latina, mas para o Sul inteiro?

Camila: Não apenas o Sul. O Brasil era respeitado também por países europeus.

Mônica: No caso da Ásia, do Timor Leste, que agora tem estudantes na UNILAB, o embaixador que foi negociar o fim da opressão sobre o Timor Leste... me fugiu o nome dele. Bem, nosso embaixador deu todo apoio ao líder revolucionário, e inclusive morreu lá.

Bas'Ilele: José Serra, quando assume, logo fala em fechar a embaixada brasileira em África. A visão dele é preconceituosa, achando que o Brasil não ganhou nada. Ora, o Brasil ganhou muito. De 2003 até 2016, a gente viu que o balanço comercial sobe para 250\% de intercâmbio. Estamos falando de dinheiro. A grande questão do paradigma desse grupo é o medo que tem, pois a política externa do governo Lula fez o quê? Fortaleceu a autoestima do brasileiro, de uma população negra brasileira, 54\% da população em dados do IBGE. No censo de 2000, a população negra, preta e parda está em torno de 44\%. Em 2015, esta população chega em torno de 54\%. Quer dizer, a política de cooperação solidária tem efeitos internamente via movimento negro brasileiro. As pessoas começam a ter autoestima, a se autodeclarar como negras. Então reforçar uma política voltada para a África nos alimenta. Falei sobre a questão da diáspora porque entre nós tinha circulação de ideias e intercâmbio, mas quando tem um governo que possibilita esses contatos de forma concreta. No governo Lula, do ponto de vista da África, houve esse retorno que se reflete na população brasileira.

Pedro Vitor: Queria ler a participação do ouvinte Marcelo Oriá, administrador. Ele comentou que fica muito triste quando pensa que discussões assim não são feitas todos os dias nos meios de comunicação brasileiros. Estamos mergulhados em um buraco profundo em que a ignorância política tem aumentado o fosso do país entre os que conseguem perceber a grande gravidade da atual conjuntura e os que estão absolutamente alheios, e isso é extremamente perigoso. Obrigado, Marcelo, pela sua participação. 
Mônica: Queria agradecer à Raquel pelo convite e por citar o embaixador Sérgio Vieira de Mello, exatamente esse nome que estava tentando lembrar por seu papel decisivo na independência e na libertação do povo do Timor Leste ${ }^{2}$. Inclusive temos um grande grupo de timorenses estudando aqui na UNILAB. Mais uma vez, Pedro, grata por suas perguntas instigantes, por nos fazer pensar e repensar.

Camila: Agradeço ao Marcelo, penso como ele. Agradeço à UFC pelo espaço que proporciona através da Rádio Debate. Uma das piores sensações que já passei foi ser silenciada no meu pensamento. A academia vive do debate, da discordância. Dentro do nosso próprio grupo de pesquisa há pessoas que concordam e discordam, e é isso que nos faz vivos. Então para mim foi uma grande honra e um prazer saber que a gente continua com esse espaço, podendo discutir e utilizar esse instrumento daqui da UFC. Fico muito grata pelo espaço.

Bas'Ilele: Agradeço a Pedro, Mônica e Camila, que proporcionaram esse tema que é a política externa brasileira. Como dizemos, esse exterior são os nossos laços brasileiros que vêm da Europa, África, Oriente Médio, de todos os cantos do mundo. Ao mesmo tempo, para entender a política externa é preciso entender a política nacional e regional e assim por diante, levando em conta as populações indígenas que fazem parte dessa nação, e ficar atento ao rumo da política.

2 Em 19 de agosto de 2003, Sérgio Vieira de Mello, funcionário das Nações Unidas, foi morto ao lado de mais 21 pessoas em um atentado a bomba em Bagdá. A Al Qaeda assumiu a responsabilidade pelo ataque e informou que o diplomata brasileiro era o principal alvo da ação. Vieira de Mello foi titular da ONU na administração de transição que transformou o Timor Leste em um país independente, entre 1999 e 2002. 